\title{
Assembly: Performing the materiality of Muslim prayer spaces
}

\author{
JULIE MARSH University of Westminster
}

\begin{abstract}
This article reflects on the significance and impact of Assembly, a site-specific research project made and exhibited in Birmingham Central Mosque, Brick Lane Mosque and Old Kent Road Mosque from 2016 to 2020. Assembly provided an opportunity for Muslims and non-Muslims to experience Jumu'ah prayer first-hand via the site performances, which temporarily dissolved the religious/social boundaries of each mosque. Each performance highlighted the differences and relations between each site, furthering ideas of performativity in Muslim prayer spaces. This article summarizes the impact reported by each mosque community as well as reflecting upon the relationships built within the wider community.
\end{abstract}

\section{INTRODUCTION}

In today's world, Islam and Islamic practices are primarily represented in their political and ideological manifestations and are characterized as modernity's 'other'. Subjected to the disciplinary gaze of Western art historians and anthropologists, the sensual, aesthetic and everyday cultures of Islam and of Muslims are often museumized or orientalized and subordinated to the realm of political ideologies.

(Moallem 2014: 1)

Mosques in the United Kingdom sit within a wider unhelpful discourse that likens them all to each other, making any one mosque representational of the many. A mosque community is not a fixed object, but is continually in the process of being made by the everyday practice of Islam, when sites of worship are reduced to representation the performative and experiential qualities are lost. Previous research into Muslim sites of worship has mostly been conducted as theological and sociological studies that fail to address the performativity of Muslim prayer.

This article reflects upon the impact of Assembly, a series of site-specific installations that perform the materiality of Muslim prayer spaces, comprising of 1:1 scaled moving floor projections with 5.1-surround sound. As the audience enters each prayer site, the projection is activated, revealing a pre-recorded film of congregational prayer. The digital moving image hovers improbably above its 'real' counterpart, providing an opportunity to experience prayer in situ, via the site-performance. Assembly to date has been made and exhibited in three mosques, Birmingham Central Mosque in 2016, Brick Lane Mosque 2018-19 and Old Kent Road Mosque in 201920. In each specific site, Assembly operates in a distinctly different manner (as object, subject, time machine, mediator, investigator and social operator), providing distinctly different techniques and outcomes in each site. The differences and relations between each site add up to a body of work that furthers ideas of performativity in Muslim prayer spaces.

In One Place after Another: Site-Specific Art and Locational Identity (2004), Miwon Kwon proposes three forms of site specificity, each relating to the different means of inhabiting and interacting with the connotations of site, expressed as the following paradigms: phenomenological, institutional and discursive. Each of these paradigms overlap and can be applied to an analysis of Assembly as the phenomenological (as an actual physical location), institutional (informed by the religious/social structures) and discursive (the theological and social issues associated with a ritual space). This article will expand Kwon's model by proposing an additional forth paradigm; the performative. This forth paradigm describes the enactment of devotional practice in Islamic ritual 
spaces. By placing the audience at the centre of both the artwork and crucially the site, Assembly evokes emotions and sensations within both the worshippers and the public audience and therefore should be assessed in terms of the affective experience.

\section{CONTEXT}

Non-haptic, non-temporal ways of representing place have come to dominate contemporary practice. In For Space (2005), geographer Doreen Massey argues that place is un-representable since in order to fix a representation of space one needs to extricate it from the temporal, to remove it in order to analyse it. Barbara Bolt (2004) presents a similar concern asking, 'Why does representation continue to operate as the seemingly unassailable and assumed truth underpinning visual practice? Is it possible, for example, to think our productions outside the paradigm of representation?' (Bolt 2004: 12). Assembly builds upon these questions via an understanding of the mosque as evolving, relational and beyond representation. It proposes that the materialization of a Muslim prayer space can be achieved through a 'performance' of the site as 'an embedded engagement in the world of which it is part' (Massey 2005: 28). In 'real space', the viewer's experience of the artwork becomes inseparable from their experience in site, an encounter measured only in the viewer's reflection upon and awareness of their own activity. The viewer must not only delineate the boundaries or limits of a work but also separate this work from their own experience of looking as 'real space cannot be experienced except in real time' (Morris 1993c: 77). The disjunction between the reading of space and the experience of space blurs the distinction between the virtual space of the work and the real space in which the viewer acts. Assembly repositions the act of representation from its retrospective or projective dimensions towards that which is performed and is experiential. The idea of space being a fluid, continual and open-ended experiencing of an environment forced the research to reconsider itself as a spatial practice if, as Simon O'Sullivan describes it, 'art is also an event in continual resistance to closure: art then is the name of the object of an encounter itself, and indeed of that which is produced by the encounter' (O'Sullivan 2006: 2). Thinking about practice in terms of event, therefore, was not simply the unfolding of a sequence of activities within the privileged and territorialized space of the gallery; the art experience needed to be rethought or re-experienced, in terms of the changing live space of the mosque. Again, where Massey talks about the representation of space, she describes how we might see it as 'no longer a process of fixing, but as an element in a continuous production, a part of itself, and itself constantly becoming', and the activity, the practice, 'an embedded engagement in the world of which it is part' (Massey 2005: 28).

Technically, the context of this research lies in the origins of early cinema, with reference to the Lumière Brothers' Cinématographe (the first three-in- one device that could record, develop and project motion pictures) and the early pioneers of cinematography, who often used the same piece of equipment to both shoot film and project it to an audience. Assembly builds upon the image making of structural filmmakers via the development of a recording/display device that is mobile. This new technique enacts a performance of space that cannot be separated from the temporal. The site-integral artworks made in this research build upon this technique by representing recorded material back in the place it was filmed using a motorized recording/playback device, allowing the representation to physically move through the site. This enables an exact transfer of scale and time as the image maps the architectural site as 'a kind of matching of the world with its representations or, rather, a bringing of the two into critical conjunction' (Hamlyn 2003: 53).

\section{METHODS}

Assembly uses the working methodology 'site-integrity' a term coined during my Ph.D. (completed in 2017). Siteintegrity performs place through the use of motorized recording/display devices in situ, enabling an exact transfer of scale and time as the image maps the architectural site. The site-integral motorized rig is essentially designed to obtain a 1:1 ratio between image and site. As the image moves through the physical space, the controlled motorization cancels out the movement of the recorded image, giving the effect of only the frame moving, constantly revealing and concealing the architectural site below. Therefore, there is never a point of fixed representation as the work is continuously in the process of being made. The experiential nature of this practice encouraged feedback from the site community during the creative act, formally employed by this study. 
Qualitative research was the most suitable method of data collection precisely because it offered an insight into subjective interpretations, human feelings and emotions, appropriate for this phenomenological study. At strategically positioned points in production, the community informed the making of the work through 'open sites', a site-specific version of an open studio. Rather than making artworks for an art audience Assembly was made with and for the mosque community, building direct social relationships with new audiences specific to the site. The congregation explicitly contributed to the process of creation, which further reinforced their authentic experience of the mosque as site. It is important to note that each community was specific to each site and the recorded interviews from these collaborations are used to support the research findings throughout this article.

\section{RESEARCH FINDINGS Assembly at Birmingham Central Mosque, Salat (2016): Performing Ritual Prayer}

Birmingham Central Mosque, one of the largest mosques in Western Europe, was built in 1969 and opened to the public in 1975. Birmingham Central Mosque was used as a pilot project for Assembly in 2016 mainly due to its multi-denomination position, which means it does not belong to any one particular sect or school of thought but it represents all Muslims from any background. Salat is the obligatory Muslim prayer, performed five times each day and became the focus of this research project.

As an artist, I was granted access to make the work, but at the same time, as a woman I was denied access to the main prayer hall during prayer. This demonstrates the complexity of negotiation in terms of engagement with the materiality of a space, when that space is determined primarily by strict codes that are based on ideological restrictions. There were strict rules to follow when filming; the camera was not permitted to film in front of people praying, nor could it show their faces. The mechanical eye allowed access to the sacred moment of prayer where focus to worship needed to be central and the camera non-intrusive. In light of this, a silent automated rig was constructed to film the Salat prayer from above at a constant speed from the entrance to the Mihrab (Figure 1). The pre-recorded footage of prayer (Figure 2) was then projected back into site using the same device, the controlled motorization of the projection re-traced the movement of the recorded image, giving the effect of only the frame moving through physical space, constantly revealing and concealing the actual site below.
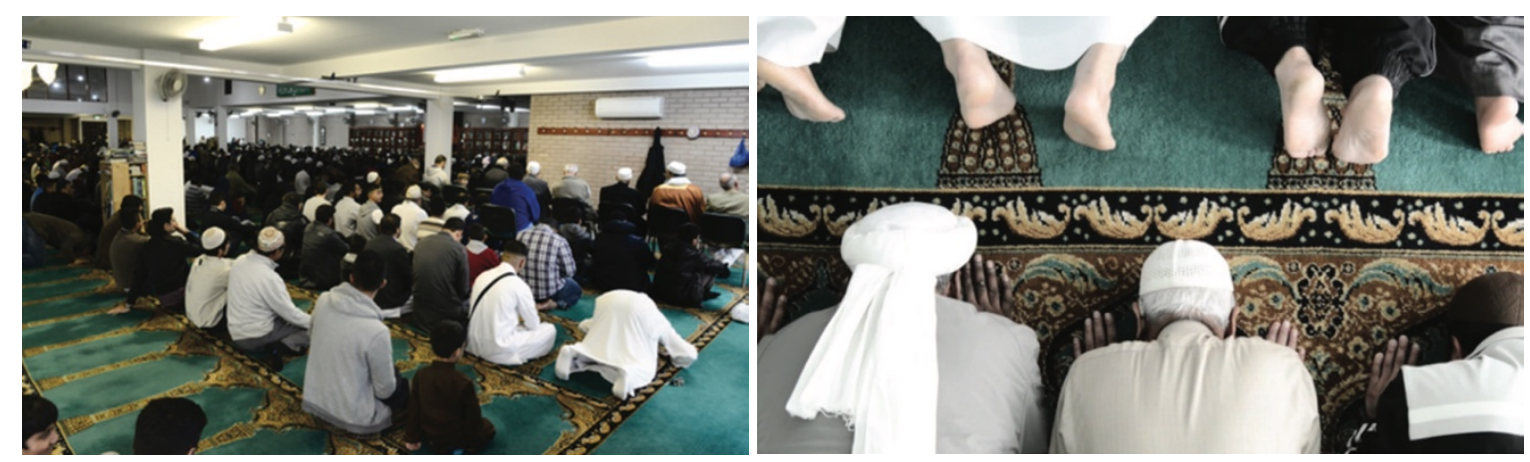

Figure 1: Filming in Birmingham Central Mosque, Marsh 2016. Figure 2: Salat (2016), Marsh 2016.

The vertical relationship between the camera and the observed worshipers called to mind the vertical axis of sacred relationships in which the spiritual higher domain was 'above' the worshipper, elevating the rig to the domain of the godly (Figure 2).

There was something very interesting happening with the projection where not only did the image seem ghostly and ephemeral but also deep. It almost seemed as though the image was being projected into the carpet rather than onto it. Maybe it had something to do with the light or the low ceiling which enhanced a downward looking, the effect summoned thoughts about the vertical space/vertical bowing (up and down) action during prayer and how these synced or became extended in the projected image. (Congregation feedback)

The projector cannot fully provide the sense of the divine revelation itself, but provides enough information for the congregation to explore many thoughts regarding worship, time, space and being. Salat challenges ideas about what should happen in a sacred space as the worshippers physically re-oriented themselves to their own 
image, witnessing the projected image of their body move over their physical body in the site. One of the worshippers discussed their bodily expectation as they 'felt' the projected image trace over them,

Experiencing the image of my own body and feeling it physically move over me was a strange feeling, I felt removed yet at the same time I was made more aware of the space around me. (Congregation feedback)

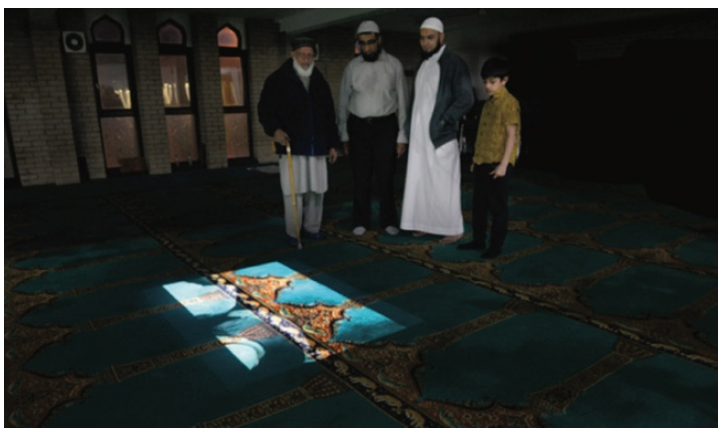

Figure 3: Site-performance with congregation, Marsh 2016.

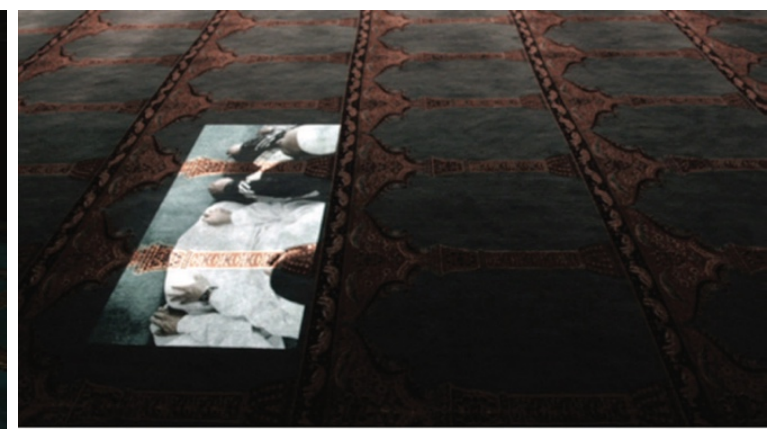

Figure 4: Detail of moving projection, Marsh, 2016

Their orientation to the moving image was both to give it space - to treat it as an object of reverence - and to intervene with it by touching and kneeling on it. The 'interaction' does not actually disturb the thing as material or the thing as image: it performs both at the same time and shows how we come to be ourselves as ethical beings through figuring out how things feel on our bodies. The worshippers experienced 'themselves' in the active sense, directly relating to their sensual and corporeal involvement as they interacted with their own image performing ritual prayer,

The projection opened my eyes to the physical act of prayer. Of movement and repetition. Because my view or senses are often fixed on a focal point (the imam), I didn't really consider my own movements until seeing the image of myself in prayer. (Congregation feedback)

The congregation questioned how their projected image of self, related to the real space and how their experience of the real was mediated by the image (Figure 3). The experience of the artwork was informed by what the congregation habitually and haptically knew about their mosque, but was also unrestrained by the physical body and physical world. The real is itself 'in language' (Le Grice 1977: 287). The texture, colour and material of the real carpet - simultaneously heightened and challenged through the projected image. This fluidity creates 'gaps' which the worshipper can see 'other' things through; the artwork and its place may be momentarily articulated one in the other. The projection helps the viewer build a mental image of the object, constructed partly through haptic memory.

Salat investigated the congregations' physical and mental awareness of self in relation to the experience of the site. The way that the projected image of the prayer mat matched the scale and proportions of the architectural site (Figure 4) made for a visceral and direct corporeal relationship between the spectator and the site. Peter Gidal expressed this point of view, arguing, 'this concept of a one-to-one relation means that there is a direct dialogue between the represented film-time and the time of the viewer in the viewing context' (Gidal 1978: 1).

Salat provided a cerebral and sensory space for the congregation to explore a highly personal relationship between body and space, helped by the fact that the people it addressed were worshippers of the mosque and therefore invested in the site. The congregation questioned how the projected image related to the real space and how the experience of the real space is mediated by the image, as one congregation member articulated,

The projected image makes prayer appear even more tangible and real than reality itself. There is a heightened sense of the theatrical within this and seeing my own body in the film is fascinating, I've never seen myself in this light before. (Congregation feedback)

The pre-recorded footage built a dialogue between the spectator and the floor projection, and illustrated how mechanical filming techniques and constructed projection installations can offer possibilities for heightening the 
worshipper's corporeal relationship to the site. The projected image appeared multi-layered, as the image of the carpet mapped perfectly with the real carpet, whereas the bodies in prayer became ghostly illusions.

The presence of people in the footage shifted the representation to be about the watching of someone else's relationship to the place as well as the viewer's relationship to the architectural site. In Screens: Viewing Media Installation Art, Kate Mondloch proposes that in projection spaces the viewer is both 'here' (embodied subjects in the material exhibition space) and 'there' (observers looking onto projection spaces). This double spatial dynamic, a bodily encounter in real time, radically reinterprets the conventional way that projection interfaces are critically described and, more importantly, experienced, 'to see differently, albeit for a moment, allows us to see anew' (Adams 1998: 101). Projected images have the potential to disrupt conventions of viewing and in so doing stage alternate and specifically active engagements with the world around us.

The moving image and illuminated surface of time-based works provoke a different type of attention, both psychologically and physiologically from other art objects. Moving image has a dual nature: on the one hand consisting of nothing more than light and audio, while on the other hand providing a window onto another world. In a moving image installation, the filmic frame reveals a world running parallel to our own lives. This meeting of the simulated world with the real world opens up many possibilities for Assembly.

\section{Assembly at Brick Lane Mosque, East London - Jamaat (2018-19): Performing the Religious and Social Structures}

The Georgian building, acquired by the Bangladeshi community in 1976, was built as a Huguenot church in 1743, and was then converted to a Methodist chapel, then a synagogue, before its current use as Brick Lane Mosque.
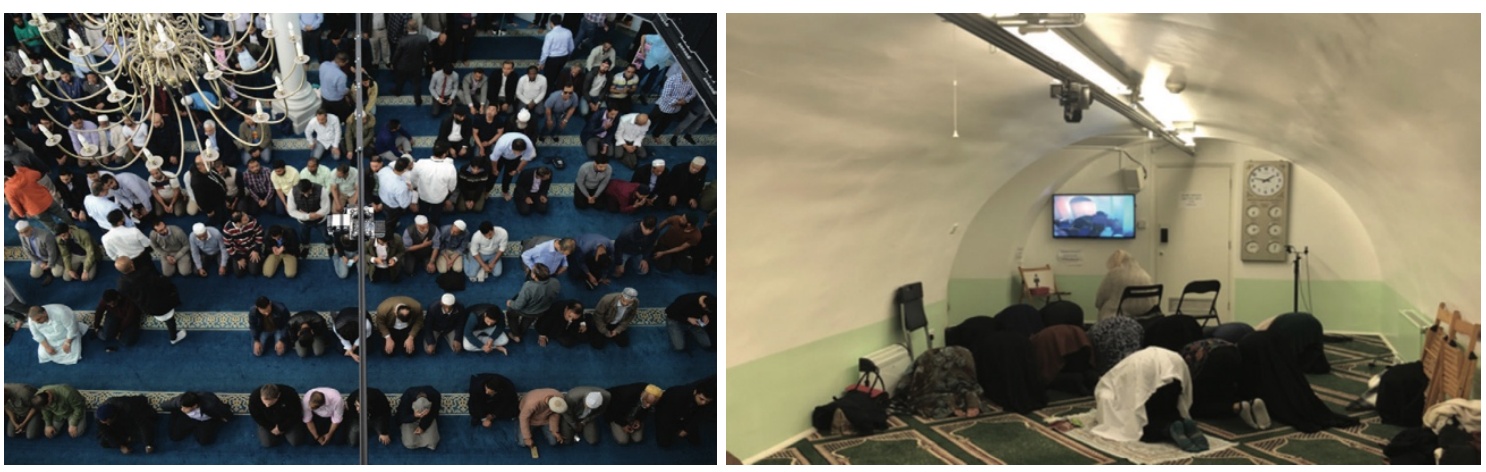

Figure 5: Filming in main prayer hall, Marsh 2018.

Figure 6: Filming in female prayer room, Marsh 2018.

Made in collaboration with the Brick Lane Mosque community, it felt appropriate to title this artwork Jamaat (a gathering or congregation) as this project was more concerned with the congregation as a whole. The same automated recording/playback method was used and adapted to fit the needs and restrictions of Brick Lane Mosque, this time resulting in two simultaneous installations, one in the main prayer hall (Figure 5) and one in the female prayer room (basement) (Figure 6), connecting and engaging both prayer spaces. As the project evolved, this spatial/temporal relationship became a fundamental aspect of the research, the two sites so different in location, size and atmosphere, joined by the synchronized performance of ritual prayer.

Finding the balance between what was and was not appropriate to happen in a mosque was one of the most complex aspects of the research. During the periods of testing (outside of prayer times), when all the lights needed to be turned off to see the projected image, some of the worshippers would ignore the film and turn the lights on to pray. A gentle reminder that this site is a religious site of prayer, not an art gallery.

At the start of the project, many members of the congregation were curious about the intention of the artwork, discussing the 'media representation' of Islam and their concerns over negative implications that the artwork might have towards their religious practice. Over time, the congregation became less anxious and more involved in the artwork's development. Male members of the congregation were also practically involved in the production, especially during the Friday Jumu'ah prayer, when I was not allowed to access to the main prayer 
hall. This involvement built a level of trust within the community and ownership of the artwork as they started to refer to the work as 'our' film,

It is something that I've been involved in over the last month or two, I always help set up the rig at the start of prayer and take it down once the filming is complete. I think our film is really effective. (Congregation member)

This sense of ownership argues for the continuing importance of belonging and locality to how people define themselves through place and unity, as one congregational member stated,

The film makes you think of unison, everyone in the whole world at this time is praying towards one direction who is a Muslim, it highlights a point which everyone is trying to work together for a good thing. (Congregation feedback)

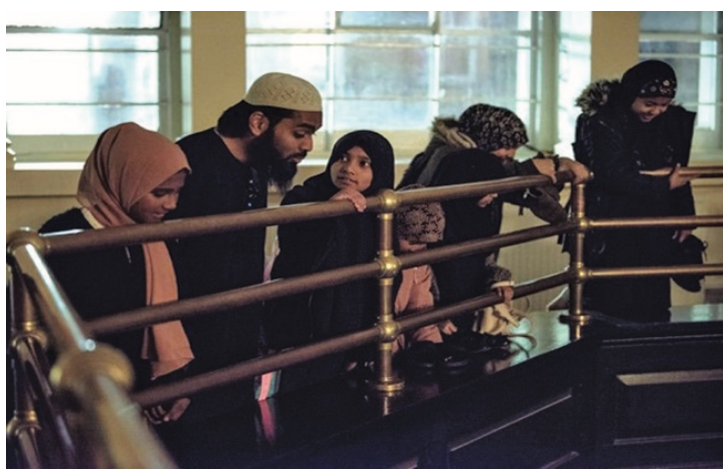

Figure 7: Congregation in conversation, Marsh 2018.

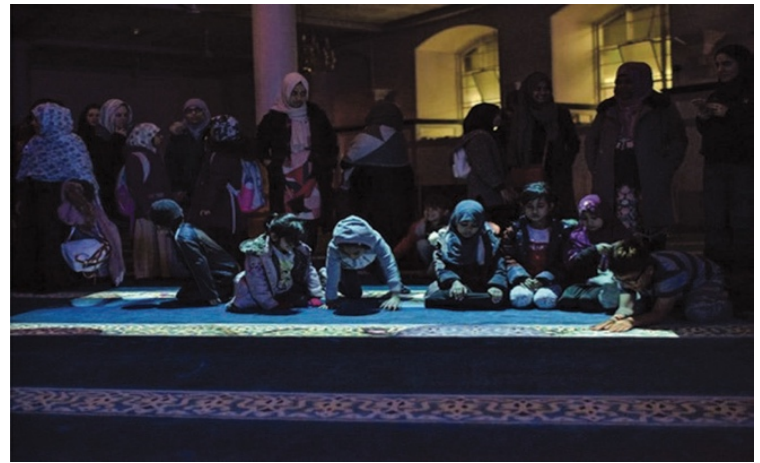

Figure 8: Female congregation in main prayer hall, Marsh 2018.

Jamaat provided an opportunity for the congregation to consider and reflect upon the religious practices and social structures present in site, providing an opportunity to engage, collaborate and share their views and opinions within their own community (Figure 7).

The research opened a genuine dialogue between the congregation as a whole, allowing men and women to experience their sacred spaces in a different and unique way,

Not only is the footage specific to Brick Lane Mosque but also the individuals who enter the prayer space jump from the surface of the projection, particularly in the women's prayer space where there are significantly fewer participants. We witness the fluidity of the congregation and can appreciate the uniqueness of the people who make up the group. (Congregation feedback)

The two site performances permitted access for men and women to both sites of worship, temporarily dissolving the gender segregation within the mosque. For most of the female congregation, this was the first time they had stood in the main prayer hall (Figure 8). For the female congregation comparisons between the two prayer spaces became a point of discussion,

The artwork reflects the contrast between prayer sites by mirror imaging the difference; the area for men upstairs, which is such a wonder- fully open physical space is actually full in the film, whereas the more confined space for us was all but empty in the film. (Congregation feedback)

Most of the female congregation accepted the invitation to enter the main prayer hall during the site performance; however, it is worth noting that the male congregation were less inclined to venture into unknown territories. This may suggest that the religious and cultural lines are much harder to dissolve from the male perspective. Issues around equality of provision were raised by some of the female congregation, with many wanting future access to the main prayer hall, while others explained why they feel more comfortable having their own separate space in light of the physical act of prayer. At the end of the residency, the Brick Lane Mosque 
community invited the general public into the main prayer hall and female prayer room, providing an opportunity for non-Muslims to also experience Jamaat first hand via the site- performances (Figures 9 and 10).

Jamaat allowed the Brick Lane Mosque to fulfil their mission 'to work closely with the community, members of different faiths and non-faith and create mutual respect, value and tolerance within the diverse community' by opening the work and site up to a public audience and local schools, as Imam Kamal Hussain discusses,

The project is very unique and special and I'm happy to be part of it. It's a new way for non-Muslims to come and see how we Muslims pray and congregate together. It is a visual and audio experience and opportunity to learn and understand Islam, through dialogue, discussion and social interaction. I'm sure people will get a moving experience out of it. (Imam Kamal Hussain, Brick Lane Mosque).

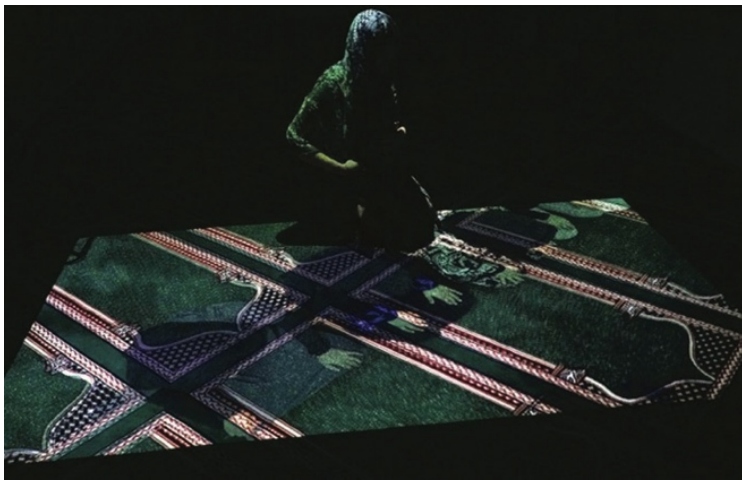

Figure 9: Site-performance, female prayer room, Marsh 2019.

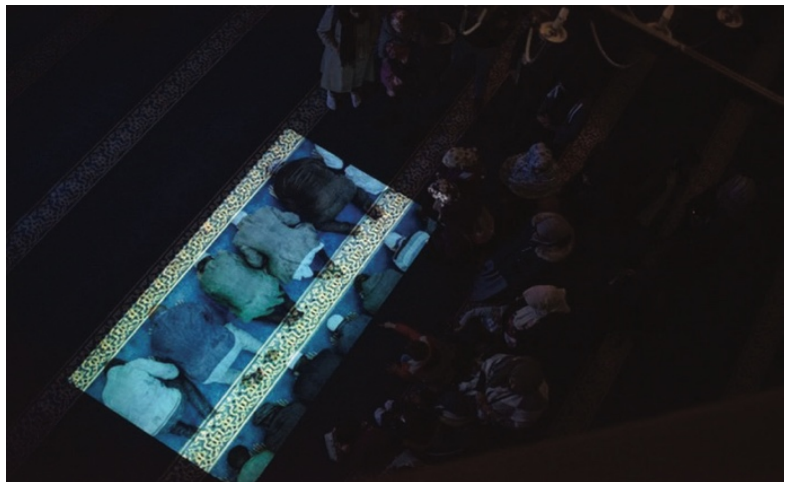

Figure 10: Site-performance, main prayer hall, Marsh 2019.

The two site performances demonstrated the congregations drive to engage in meaningful dialogue with the general public via the artwork, breaking traditional stereotypes, as one local resident stated, 'It was a very special and moving experience, especially the way the congregation interacted with us, it was very beautiful how they welcomed us into their space' (Audience feedback). The public's reception of the artwork was mediated through the openness of the mosque community, creating a platform for reflection and debate.

Assembly dissolved the perception that the mosque is a 'no-go area' outside of the Muslim community, which provided an opportunity for non-Muslims to understand the religious practices taking place, without feeling like a voyeur. As a member of the public described,

I was always curious to see and know what was taking place, but it was obviously a strict no-go area. Having the opportunity to witness prayer through Assembly, and not feel as though I was intruding was really incredible. I found it a rare, meditative and moving experience. (Audience feedback)

The local community, although cautious, showed interest in both the male and the female prayer spaces, spending equal amounts of time in each site. The artwork became a point of reflection for a deeper understanding of Islamic faith and culture, challenging social perceptions that might unconsciously exist. The success of this site-performance was also dependent on the audiences' will to engage (Figures 11 and 12). In 'Wisdom Sits in Places: Notes on a Western Apache Landscape' (1996), anthropologist Keith Basso describes what he calls a process of 'interanimation' that occurs between individuals and specific places. Once we begin to pay attention to a place, it comes to generate its own field of meaning. This is how a place is brought to life, 'animated by the thoughts and feelings of persons who attend to them' (Basso 1996: 56). Basso asserts that we can engage with place by paying attention to the 'sensing' of it. He claims that relationships to places are 'most richly lived and surely felt' (Basso 1996: 54) when people make them the object of awareness and reflection, 'when individuals step back from the flow of everyday experience and attend self- consciously to places' (Basso 1996: $54)$. 

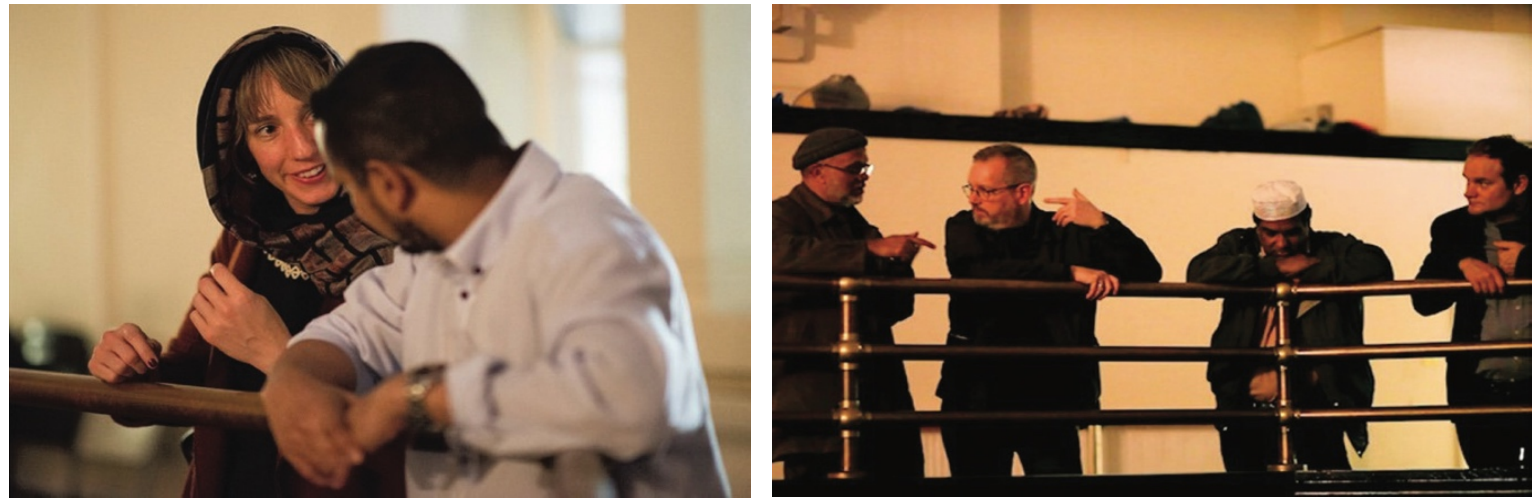

Figure 11: Congregation in conversation with public, Marsh 2019. Figure 12: In conversation with public audience, Marsh 2019.

The importance of sharing cultures and establishing deeper relationships within the younger generation was evidenced during the local school visit where over 40 primary school children, staff and parents visited the artwork (Figure 13). One mother reflects on how important art is for children as a way to share their identities, especially when they have different cultural backgrounds, 'I loved seeing the children playing in and around the films and I loved Stella's friends clearly being both proud to show her round the mosque and also simply enjoying being together'. The madrasah pupils gained a sense of belonging and pride as they showed the visiting children 'their mosque' while the local schoolchildren learned about Islamic faith and culture (Figure 14).

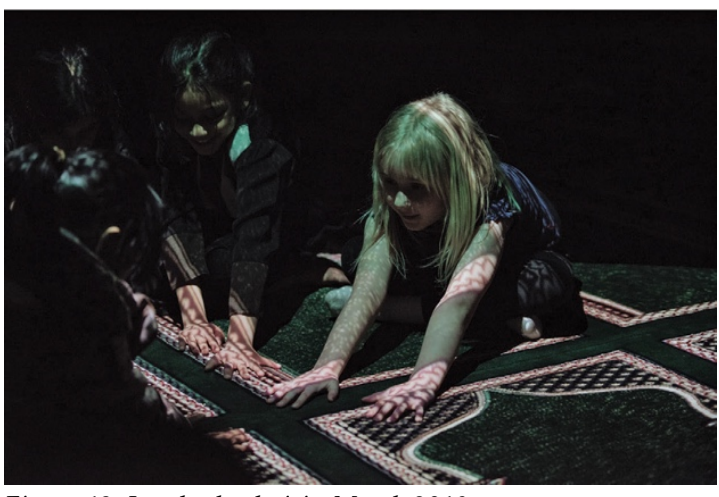

Figure 13: Local school visit, Marsh 2019.

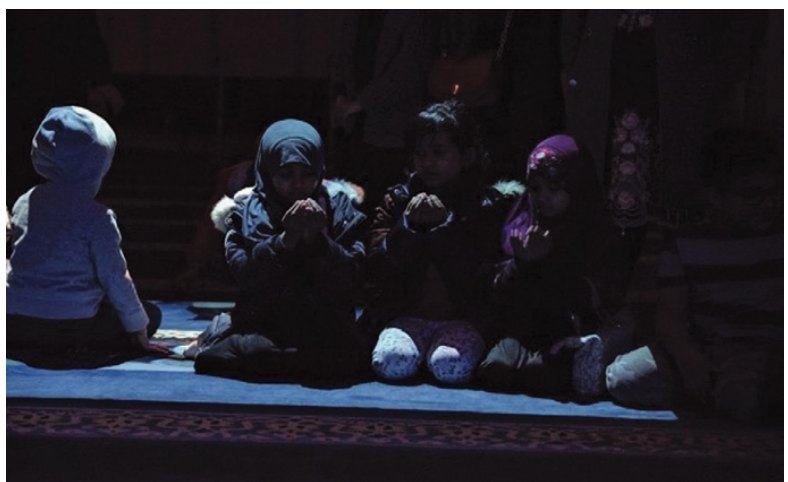

Figure 14: Children interacting, Marsh 2019.

The project also provided a platform for associated parties, such as Everyday Muslim and the Inclusive Mosque Initiative (dedicated to creating places of worship for marginalized Muslim communities, spiritual practice and the promotion of inclusive Islamic principles) to help gain valuable feedback into the ethical development of the project,

If Jamaat were to be shown in a gallery, it would take on an entirely different meaning, one we wouldn't be comfortable with. However, the bird's eye view used to create the footage - fittingly called the 'godshot' in the film industry - shows us ourselves in a unique and unfamiliar way that's worth experiencing. Site-integrity attempts to avoid fixed representation and with Jamaat, it succeeds. (Naima Khan, Inclusive Mosque Initiative).

The Inclusive Mosque Initiative's contribution to the discussion of Assembly also helped them to build a relationship and create a sense of solidarity with Brick Lane Mosque, which resulted in open access to the top floor of the main prayer hall, in quieter periods, for the female congregation and greater disabled access throughout the mosque.

\section{Old Kent Road Mosque: Performing the material site}

In September 2019, Assembly moved to a new site; Old Kent Road Mosque located in a renovated former pub in Southwark (Figures 15 and 16). The Nigerian Muslim association informally started in the early 1960s with a 
transient community of Nigerians coming to London to study. Initially staying only for short periods of time, it was not until the 1980s when a more permanent community started to develop. It took a further 10 years before the association in 1993 acquired their first place of worship and another 5 years after that before the abandoned pub was established as Old Kent Road Mosque.

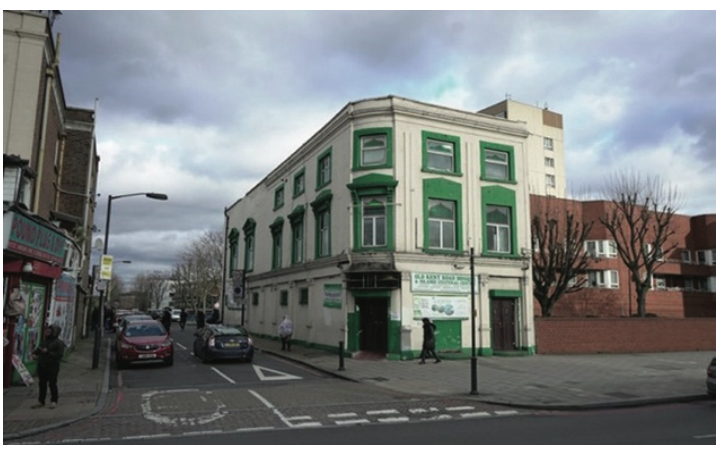

Figure 15: Old Kent Road Mosque, Marsh 2019.

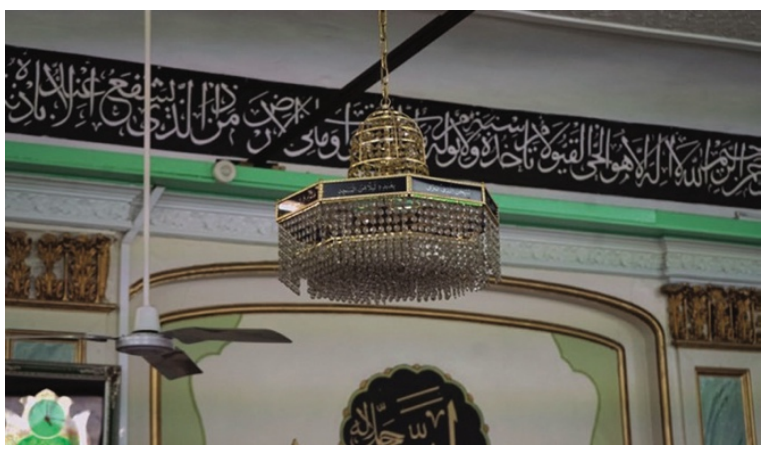

Figure 16: Interior of Main prayer hall, Marsh 2019.

Mosques in Britain are crowd-sourced community projects. There is no overarching religious authority that directs or funds mosque buildings, religious congregations are independent and self-organized. As a result, mosques built by immigrant communities have adapted to and altered the British vernacular, and can be found in terraced houses, supermarkets and pubs. In this context Assembly serves as a performance and record of the architecture, social history and material culture of Muslim communities.

A new purpose-built mosque and Islamic centre is due to be built on the existing site of Old Kent Road Mosque in 2020. Assembly will perform both the main prayer hall (Figure 17) and the female prayer hall (Figure 18) before the building is demolished. The female congregation at Old Kent Road Mosque has built a large, active community, organizing many support groups and events. Their prayer space is of equal size and capacity to the main prayer hall directly above. An LCD monitor connects the two spaces as the imam is broadcast live in the female space. Identical rigs will be made in both spaces to reflect the unison of the two congregations via dual moving projections performing both prayer sites in synchronized time and space.

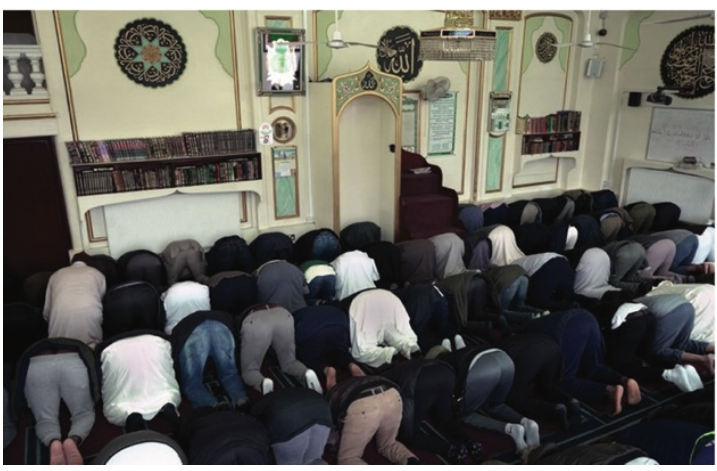

Figure 17: Main prayer hall, Marsh 2019.

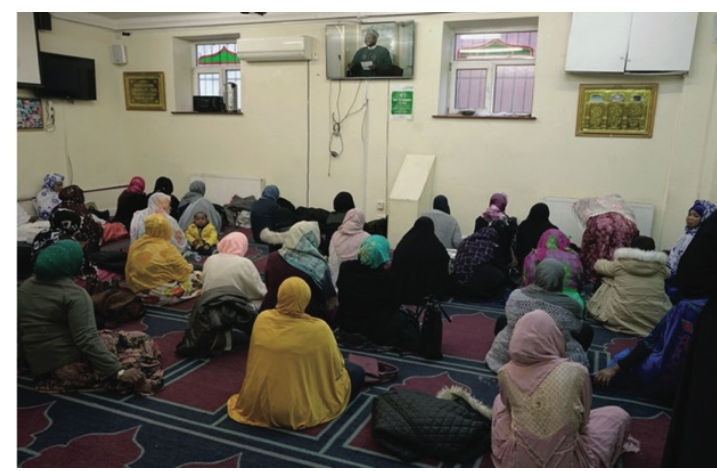

Figure 18: Female prayer hall, Marsh 2019.

Alongside the site-performance, a second artwork will be made off site, re-performing Assembly using the original carpet from Old Kent Road Mosque. This will allow Assembly to develop the scope and breadth of siteintegrity as a concept, by investigating ways that site can be 'transported' to another location via the recording/playback device. The carpet design represents a door- way with the form of an arch that indicates the direction to face during prayer, reminiscent of the Mihrab. With its orientation towards Mecca, the prayer rug acts as a temporary place of worship outside the mosque. It is a portable sacred ground that can be used at any time, isolating worshippers from their immediate surroundings, transporting them symbolically elsewhere. The word 'mosque' from the Arabic word 'masjid' means 'a place of prostration in prayer'. A mosque, therefore, is not the architectural building; it is the site of prayer, where the body is placed in a submissively prone position as a gesture. This research will ask the question, is it possible to activate an embodied experience by performing the prayer carpet? 


\section{CONCLUSION}

To date, Assembly has been made in three functioning mosques, Birmingham Central, Brick Lane and Old Kent Road, the fabric of each building untouched, its ascribed function undisturbed. Situating itself as being borne out of an adherence to the integrity of each site Assembly follows the demands made upon it in order not to disturb the place. The fact that the artworks are allowed to be produced in the mosques suggests an openness of Islam to something that might seem to intervene quite radically in the worshippers' sense of communion. This also raises important questions concerning the site's materiality; how much are the religious practices responsible for making the place and therefore integral to it? It could be argued that there is already a form of site-integrity in each mosque because of the religious and social practices that happen there; the performance of worship makes it a mosque. In Assembly, site-integrity adds another layer of the activity that is already taking place, exploring a tension between hegemonic ideas about what is appropriate to happen in a mosque - versus artistic engagement.

The act of worship within each mosque is constitutive to its existence and therefore Assembly should not be regarded as a representation of a space, and still less one of individual worshipers, but rather as an attempt to perform the mosque as it actually exists. Both the buildings and the communities it forms are re-assembled each time the piece is performed, each made and re-made in a relational process between the audience, artwork, worshippers and site. The temporal dimension of each site performance is a vital component of the experience, as it is a re-projection of the exact architectural space in synchronized time. This has a considerable effect on the mosque as the artwork deconstructs the familiar frame of reference, subsequently affecting the congregations' material relationship with the physical site of the mosque prayer rooms.

The pre-recorded footage of people in prayer projected back into the architectural site prompts the worshippers to question what is real and what is illusion. This invites a questioning of the real in time and space and extends Le Grice's view of the potential existing between the imagery and the space of encounter,

The juxtaposition of the representation and the real, in certain Expanded Cinema work, made illusionary representation and the spectator's encounter with the actuality of a work the central aesthetic problem. [...] In retrospect, the conflict between representation as 'illusion' and the 'real' object could now be seen as one strategy for initiating a philosophical/aesthetic discourse in the experience of the work. This includes awareness that the insecurity of the representation is transferred to the 'real'. The real is itself mediated through the symbolic. The real is itself 'in language. (Le Grice 1977: 287)

Ontologically, there can be no split between representation and the real, however, we experience the 'realness of the real' and the 'image-ness of the image' and Assembly pays attention to this. Willian Raban refers to this experience as mise en abyme, which literally translates from French into place of the abyss. The phrase is typically used to describe the visual and haptic sensation of standing between two mirrors that extend into infinite space. In relation to film, Raban suggests the mise en abyme exists between filmic time-space and real or projected timespace,

The primary experience of watching and the secondary experience of representation are to some extent merged [...] immediate past is fused with immediate present to create what Raban calls a 'mise en abyme [...] of space and time'. More to the point the work sets up a tension between space, time and the medium. (Curtis 2011: 29)

Mise en abyme has largely been discussed as a cinematic experience built up by duplicating the cinematic space between and around the projector and the projection screen or by using the same devices for filming and projecting and in Raban's work, mise en abyme is generated through responsiveness to the architectural site. Nicky Hamlyn describes this aspect of Raban's work as site- specific and sees the rarity of artists working in this way: 'it is obviously the case that many moving image works are inspired by a particular location, it is relatively rare for those works to be shown in the place where they were shot: to address the unique circumstances of their time and place of presentation' (Hamlyn 2003: 26). 
Assembly investigates explorations in space and time to produce an experience that leads to a shift in awareness, a physical and mental re-positioning in relation to the mosque. It is futile to critically engage with the work by trying to contour how its material productions of site-machine-audience 'challenge' hegemonic representations but it seems worth reiterating that by definition, the site-performance calls into question how fidelity to a representation, sacred or otherwise, necessarily entails its subjective restaging. The work 'submits' to the vagaries of space yet this gives it power to call the space into question. In Assembly place is apparatus - i.e., it depends on which elements are operationalized at a particular time and it should be assessed in terms of how it makes subjects in situ feel rather than be reduced to its apparent attributes - there are just momentary integrities which need to be felt and to be understood (with the caveat that 'understanding' is not the modus through which that power works over the body. It is a different logic, one that works through orientation and bodily feeling).

Each site-performance becomes both metaphor for wider social formations and a physical apparatus that, momentarily at least, pushes the viewer in a different direction. Ritual sites are anchored in cultural and social traditions that integrate multiple narratives of place and self. The encounter of art in a Muslim prayer space brings a self-reflexive aesthetic experience activated by ritual. It could be argued that each mosque simultaneously becomes a place of contemplation, reflection, interaction, production and event. Assembly feeds into the context of site-specific art and proposes a new paradigm 'the performative' which artists could use to actively engage site and audience within the creation and reception of artworks.

\section{REFERENCES}

Adams, Parveen (1998), 'Bruce Nauman and the object of anxiety', October, 83: Winter, Cambridge, MA: MIT Press, pp. 96-133.

Basso, Keith (1996), 'Wisdom sits in places: Notes on a western apache lands- cape', in K. Basso and S. Feld (eds), Senses of Place, Santa Fe, NM: School of American Research Press, pp. 53-90.

Bolt, Barbara (2004), Art Beyond Representation: The Performative Power of the Image, New York: I.B. Tauris.

Brick Lane Jamme Masjid (n.d.), 'Our aim and vision', Brick Lane Jamme Masjid, http://bricklanejammemasjid.org.uk/object. Accessed 21 December 2019.

Connolly, Maeve (2009), The Place of Artists' Cinema: Space, Site and Screen, Bristol: Intellect.

Curtis, David, Rees, Alan Leonard, White, Duncan and Ball, Steven (eds) (2011), Expanded Cinema: Art, Performance, Film, London: Tate Gallery.

Friedberg, Anne (2009), The Virtual Window from Alberti to Microsoft, Cambridge, MA: MIT Press.

Gidal, Peter (1978), Structural Film Anthology, London: British Film Institute. Hamlyn, Nicky (2003), Film Art Phenomena, London: British Film Institute. - - - (2006), 'A line through my work', in J. Hatfield and S. Littman (eds),

Experimental Film and Video: An Anthology, New Barnet: John Libbey

Publishing, pp. 36-46.

Kwon, Miwon (2004), One Place after Another: Site Specific Art and Locational

Identity, Cambridge, MA: MIT Press.

Le Grice, Malcolm (1977), Abstract Film and Beyond, London: MIT Press. Massey, Doreen (2004), 'Geographies of responsibility', Geografiska Annaler:

Series B, Human Geography, 86:1, pp. 5-18.

$---(2005)$, For Space, London: Sage.

Moallem, Minoo (2014), 'Praying through the senses: The Prayer Rug/Carpet 
and the Converging Territories of the material and the spiritual', An Online Journal of the Centre for the Study of Material and Visual Cultures of Religion, mavcor.yale.edu. Accessed 22 December 2019.

Mondloch, Kate (2010), Screens: Viewing Media Installation, Art, Minneapolis, MN: University of Minnesota Press.

Morris, Robert ([1978] 1993), The Present Tense of Space in Robert Morris Continuous Project Altered Daily: The Writings of Robert Morris, London: MIT Press.

O'Sullivan, Simon (2006), Art Encounters Deleuze and Guattari - Thought beyond Representation, New York: Palgrave Macmillan.

Soja, Edward W. (1996), Thirdspace: Journeys to Los Angeles and Other Real-and-Imagined Places, Hoboken, NJ: Wiley-Blackwell.

\section{SUGGESTED CITATION}

Marsh, Julie (2018), 'Assembly: Performing the materiality of Muslim prayer spaces', Scene, 6:2, pp. 133-151, doi: https://doi.org/10.1386/scene_00014_1

\section{CONTRIBUTOR DETAILS}

Julie Marsh is a senior lecturer and researcher at the Centre for Research and Education in Arts and Media (CREAM) at the University of Westminster. Through the exploration of real and representational space, she investigates how technical machines can perform site, creating critical experiences

for audiences that open debate and question social spaces. Julie completed her practice-based Ph.D. in 2017 from the University of the Arts London, where she coined site-integrity as a working methodology. Site-integrity is essentially a performance art practice where technology, artist and audience are engaged in the completion of the artwork. Recent exhibitions include Assembly, Brick Lane Mosque, London, Risk Change, KIBLA (Association for Culture and Education), Slovenia, SCREEN Moving Image Festival, Barcelona, The Biennial for Emerging Arts, Romania, Lokomotywownia, The Starmach Gallery, Krakow, Black Box Symposium, CAS (Centre for Audio-visual Studies), FAMU, Prague, Cinenova, LUX Moving Image, London, Sputnik-Kino, Berlin Short Film Festival, Moving Sites/Sights, Meetfactory and International Centre of Contemporary Art, Prague.

Contact: University of Westminster, Harrow Campus, Watford Road, Northwick Park, Middlesex, HA1 3TP, UK. E-mail: J.Marsh@westminster.ac.uk 